\title{
Inflammatory bowel disease versus chronic enteropathy in dogs: Are they one and the same?
}

\begin{abstract}
The aim of this review is to discuss why 'chronic enteropathy' might be a better term than 'inflammatory bowel disease' in dogs, because the treatment and outcome of the disease is very different from that of inflammatory boyel disease in humans. The effect of food, antibiotics, and immunosuppressant drugs on chronic enteropathy will be reviewed. New treatments under investigation will also be introduced. Although there are several studies evaluating treatment of chronic enteropathy in dogs, the quality and quantity of evidence supporting individual therapies remains scarce and more work is needed to improve management of this disease. Finally, new findings about dogs with chronic enteropathy complicated by protein losing enteropathy will be discussed. Although prognosis for these dogs is poor, recent data might help improve their treatment.
\end{abstract}

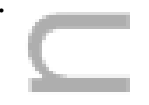

Keywords: Canine, Medicine-Gastroenterology

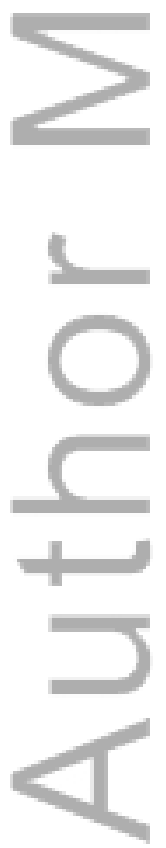

This is the author manuscript accepted for publication and has undergone full peer review but has not been through the copyediting, typesetting, pagination and proofreading process, which may lead to differences between this version and the Version of Record. Please cite this article as doi: 10.1111/jsap.12588 
Canine chronic enteropathy- is it the same as the human disease?

Inflammatory bowel disease (IBD) in humans includes two different chronic disorders characterised by inflammation of the intestinal wall: Crohn's disease (CD) and ulcerative colitis (UC). Like humans, dogs also develop chronic (defined as longer than 3 weeks) enteropathy (CE) characterised by clinical signs such as vomiting, diarrhoea, borborygmus, hyporexia, abdominal pain, nausea and/or weight loss. Chronic enteropathy is diagnosed after exclusion of extra-intestinal (such as hepatic, pancreatic or renal disease, hypoadrenocorticism and hypercalcaemia), infectious or parasitic diseases and intestinal disease of other aetiology (examples include mechanical obstruction from intussusception, foreign body or intestinal tumours (Simpson and Jergens, 2011)). One UK referral centre examining breed predisposition for CE reported increased odds ratios for developing disease in Weimaraner, rottweiler, German shepherd dog, Border collie and boxer breeds (Kathrani et al., 2011).

The current concept is that an idiopathic inflammation develops in a genetically predisposed patient, triggered by interactions between food components, environmental factors, and intestinal microbiota (de Souza and Fiocchi, 2016). The clinical signs result from uncontrolled inflammation. The aetiology of CE is suspected to be similar in dogs, as reviewed elsewhere by using the term IBD (Jergens and Simpson, 2012).

However, there are some important differences between dogs and humans that need to be highlighted. Firstly, medical therapy is central to the management of the human conditions and is aimed at controlling the inflammation. Different types of immunosuppressant drugs are used alone or in combination to first induce and then maintain remission (Grevenitis et al., 2015). Previously, treatment response was defined by clinical response alone, but there is now evidence that achieving mucosal healing is important to reduce relapse rates in IBD patients (Dave and Loftus, 2012). Current research is investigating whether more aggressive immunosuppression early in the disease course improves outcome (Grevenitis et al., 2015). In contrast, the majority of dogs will not require any treatment other than dietary modification. A further subset improves 
with antibiotic therapy and a small proportion will require immunosuppressant treatment, as reviewed elsewhere (Jergens and Simpson, 2012). Figure 1 highlights the differences in stepwise application of treatment modalities between dogs and humans.

Secondly, it is estimated that 40 to $50 \%$ of human patients with IBD will undergo surgery within 10 years of diagnosis, with a risk of recurrence of about $50 \%$ within 10 years (Annese et al., 2016). Although there is some evidence that this percentage might be reducing with a more widespread use of immunosuppressant therapy this is still very different from dogs in which the need for surgery is extremely rare (Vester-Andersen et al., 2014, Watson et al., 2014).

\section{Why use the term 'chronic enteropathy' rather than 'inflammatory bowel disease' in dogs?}

Because of the differences between dogs and human in regards to treatment and the need for surgery to control clinical signs, it can be misleading to use the term 'inflammatory bowel disease' in dogs. In effect, most dogs with this disease will NOT need immunosuppressant treatment. For this reason, CE is often used instead to describe dogs with chronic gastro-intestinal signs. The advantages of using this term are:

(1) It can be used for animals in which intestinal inflammation is suspected but has not been documented (i.e. no biopsies have been taken).

(2) It does not infer which treatment will be needed to control clinical signs.

When the term inflammatory bowel disease is used for dogs, it typically implies that treatment trials with diet and subsequently antibiotics have failed, inflammation has been demonstrated and an immunosuppressant will be needed.

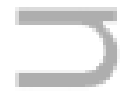

$\mathrm{CE}$ can further be subdivided retrospectively by response to treatment (Fig 2) into:

- Food-responsive enteropathy: FRE. 
- Antibiotic-responsive enteropathy: ARE.

- Immunosuppressant-responsive enteropathy: IRE (dogs responding to steroids, usually reported as steroid responsive diarrhoea (SRD), are included in this group).

- Non-responsive enteropathy: NRE.

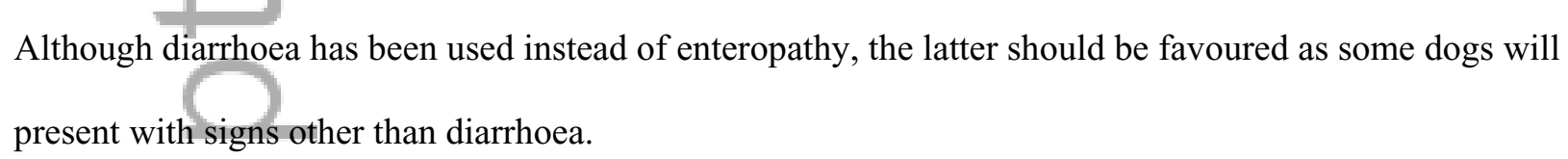

Knowing that a majority of dogs do not require immunosuppressant treatment, most clinicians will favour treatment trials first. Endoscopy or surgery is used to obtain biopsies in poor or non-responders to confirm the presence and type of intestinal inflammation and to rule out diffuse intestinal tumours such as lymphoma (Simpson and Jergens, 2011). Histology has been shown not to help in differentiating FRE from ARE or IRE (Luckschander et al., 2006, Allenspach et al., 2007, Schreiner et al., 2008). For this reason endoscopy, although minimally invasive, is best reserved for animals that have failed diet and antibiotic trials. Exceptions include dogs with severe disease when there might not be enough time to conduct a treatment trial (e.g. protein losing enteropathy) or if there is a high suspicion of a neoplastic aetiology or infectious contribution to disease (e.g. granulomatous colitis in predisposed breeds).

Reported negative prognosis factors for dogs with CE include: high canine IBD activity index (CIBDAI), marked endoscopic disease in the duodenum, hypocobalaminaemia, hypoalbuminaemia, and hypovitaminosis D (Jergens et al., 2003, Craven et al., 2004, Allenspach et al., 2007, Titmarsh et al., 2015). Subsequently, a 
revised clinical score has been defined that takes into account some of these findings: the canine chronic enteropathy clinical activity index (CCECAI) (Allenspach et al., 2007). Both the CIBDAI and CCECAI have now been widely accepted and are used to assess clinical response to treatment.

As mentionēd abôve, hypoalbuminaemia is a negative prognostic factor and poor outcome has been reported for dogs with protein losing enteropathy (PLE). Furthermore, significantly lower vitamin D concentration in dogs with PLE has been reported although its relationship with survival has not been studied (Gow et al., 2011). Median survival times of less than 6 months or a 1-year survival of less than $50 \%$ have been reported (Littman et al., 2000, Dijkstra et al., 2010, Goodwin et al., 2011, Equilino et al., 2015). However, two abstracts report median survival times of over a year (Owens et al., 2011, Stroda et al., 2012). Long-term responders (12 out of 23 dogs with median survival times of 44 months) have been reported amongst Yorkshire terriers treated with prednisolone in conjunction with diet and metronidazole (Simmerson et al., 2014). Typically, PLE dogs will often undergo endoscopy at time of diagnosis and aggressive treatment with both diet modification and early use of immunosuppressant treatment because of their guarded prognosis (Dossin and Lavoue, 2011). However, some of these dogs might respond to diet alone as outlined later. In the rest of this article, publications on food, antibiotic, and immunosuppressant therapies will be reviewed and data for dogs with CE and PLE will be discussed. PLE is used in this review for dogs diagnosed with protein losing enteropathy after exclusion of neoplastic, parasitic, or infectious disease as reviewed elsewhere ((Dossin and Lavoue, 2011). The level of evidence for the studies will follow the guidelines from Elsevier ${ }^{\circledR}$ as summarised in Table 1 (http://cdn.elsevier.com/promis misc/623124los.pdf).

\section{Food-responsive enteropathy in dogs with CE}

A marked response to diet change alone in over $50 \%$ of $\mathrm{CE}$ dogs has been now shown in multiple referral centres around the world (Marks et al., 2002, Allenspach et al., 2007, Mandigers et al., 2010, Allenspach et al., 2016). Studies using diet as first-line therapy are summarised in Table 2 with very good long term 
response (up to 3 years follow-up) in dogs fed different types of hydrolysed or novel antigen diets (Allenspach et al., 2007, Mandigers et al., 2010). In the study by Mandigers et al. (2010) the outcome was much better in comparison to an easily digestible, but non-exclusion diet (Table 2 for details). Most of these studies are prospective, although not blinded, and the high response rate and long term response support diet as a first line treatment. In several reports, FRE dogs are younger than IRE dogs and frequently present with signs of large bowel disease (Munster et al., 2006, Allenspach et al., 2007, Allenspach et al., 2016). Furthermore, they typically have lower CCECAI and normal albumin concentration compared to dogs with ARE or IRE (Allenspach et al., 2007, Allenspach et al., 2016).

It is unclear if there is a benefit of using hydrolysed diet (aiming at breaking down proteins into peptides to reduce antigenic reaction) over a novel antigen diet (new protein and carbohydrate source). More detailed information on the subject can be found in another review (Gaschen and Merchant, 2011). Studies with both types of diet have had good outcomes (Table 2) and one study did not find a significant difference to clinical response between novel antigen or hydrolysed diet (Allenspach et al., 2016).

Clinically most FRE dogs respond within a few days but may take up to 14 days (Marks et al., 2002, Allenspach et al., 2007, Allenspach et al., 2016). This information needs to be relayed to the owner to increase owner compliance during the trial and improve success. This is the likely reason why 9 dogs did respond to a stringent diet after referral although they had had previously unsuccessful diet trials (Mandigers et al., 2010). Some dogs can be returned to their previous diet (from 31\% to $75 \%$ ) after a 12 week diet trial (Luckschander et al., 2006, Mandigers et al., 2010, Allenspach et al., 2016). There is no method currently to determine if a dog is going to relapse after challenge. For this reason, many owners elect to keep their dog on the new diet once the clinical signs are controlled. If the animal is given a home-cooked diet long-term, discussion with a nutritionist is needed to ensure correct balance between all essential nutrients. It is also worth considering measuring cobalamin concentration and supplement as necessary. Cobalamin concentration can also be used at a later stage for monitoring purposes. There is some evidence that cobalamin supplementation may improve clinical signs in hypocobalaminaemic cats with $\mathrm{CE}$ and for this reason it might also be safer to supplement 
hypocobalaminaemic dogs although there is currently no evidence to support a benefit in this species (Ruaux, 2013).

As previously mentioned, the aim in humans with IBD has shifted from clinical resolution to histological resolution over the past years (Dave and Loftus, 2012). One study examined the pathological changes in duodenal biopsies of 20 dogs with FRE before and after treatment (Walker et al., 2013). The authors examined histopathological, immunohistochemical, and ultrastructural changes. There was a decrease in the mean mononuclear cell score (although not the overall histological score) and significant improvement in ultrastructural lesions within 6 weeks of diet change. This is the most in-depth study examining the effect of diet on pathological changes in the intestine and supports not only clinical resolution, but also brush border healing with diet change alone. Other studies have compared histological score after clinical resolution in FRE and SRE dogs and, similarly, no significant improvement in histologic grading was found after treatment (Schreiner et al., 2008, Garcia-Sancho et al., 2007, Allenspach et al., 2007). This raises the question as to whether longer treatment duration is needed for histological mucosal healing (repeat endoscopy was performed within a maximum of four months in these studies) although ultrastructural changes might resolve faster. These findings highlight the limited information gained from repeat endoscopy in the current state of knowledge.

In summary, these data are highly supportive of a diet trial as first step in dogs with CE as long as the animal is clinically stable and appetite is present. In FRE dogs, which are the majority of dogs with CE, some improvement is expected to be seen quickly (i.e. within days) and usually no additional treatment is necessary. Although some dogs can be reverted to their previous diets after 12 weeks, this remains a trial and error approach.

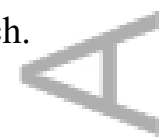

Food-responsive enteropathy in dogs with PLE 
The main histological findings in PLE dogs include lymphangiectasia (primary or secondary to inflammatory infiltration), inflammation, neoplasia, and crypt abscesses (Dossin and Lavoue, 2011). Diet trials with hydrolysed or novel-antigen food as the sole treatment are seldom attempted because of the guarded prognosis and the risk of rapid deterioration. An exception might be in cases with primary lymphangiectesia (without an identified underlying process) in which good success has been reported with an ultra-low fat diet (Peterson and Willard, 2003). However, lymph leakage can trigger intestinal inflammation and worsen the clinical picture with time (Van Kruiningen et al., 1984). For this reason, corticosteroids are often used concurrently until the clinical signs are controlled and so data on the effect of food alone are scarce. One retrospective study examined dogs with lymphangiectesia fed a low fat diet or ultra-low fat diet (Okanishi et al., 2014) together with prednisolone and metronidazole in dogs that did not respond or relapsed during corticosteroids tapering. No difference was seen in outcome between the 2 diets, with $79 \%$ of dogs improving during the 2 month study. Dogs fed the ultra-low fat diet had significantly higher albumin concentration 2 months after starting treatment. Although this study was not designed to look at the effect of diet alone, it supports the importance of dietary management to control clinical signs.

One abstract reported retrospectively the effect of diet alone in Yorkshire terriers with PLE (Rudinsky et al., 2014). Complete resolution of clinical signs was reported with dietary management alone (see Table 2 for the diets used) in 8 out of $11 \mathrm{dogs}$ (duration of the study is unknown). Another study also mentioned complete remission of 2 dogs with PLE with diet alone (Simpson and Jergens, 2011) and I have also seen similar cases in breeds other than Yorkshire terriers.

In summary, there is very little information published about dogs with PLE treated solely with diet change. However, it seems that some Yorkshire terriers will respond without adjunctive treatment for a long duration (Rudinsky et al., 2014), which might also be the case in other breeds. The central question is to determine how to select dogs for diet trial alone knowing that the prognosis for PLE is guarded and progression of disease can 
be rapid and fatal (Dossin and Lavoue, 2011, Nakashima et al., 2015). My opinion is that diet trial might be considered in dogs with PLE if they are clinically well and have good appetite. If there is no improvement within a week (resolution of gastro-intestinal signs and increase in albumin) or the animal deteriorates, intestinal biopsy would be strongly recommended if not already obtained. This helps to rule out neoplastic disease and to direct treatment as immunosuppressant drugs (with or without antibiotics) are likely to be required for ongoing management of these cases.

\section{Antibiotic-responsive enteropathy - in dogs with $\mathrm{CE}$}

Antibiotics are often used as a second-line treatment if diet change has failed or only a partial response is observed. Oxytetracycline, metronidazole, and tylosin are generally used (Table 3). The exact role of the antibiotic remains unclear. Possible effects include modification of the gut flora through anti-microbial effect and modulation of the immune-system. The reader is referred to 2 recent reviews on the subject for further information (Hall, 2011, Honneffer et al., 2014).

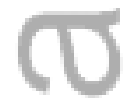

Granulomatous colitis of boxers is the only CE in which bacterial invasion of the intestinal wall has been documented with resolution of clinical signs apparent after clearance of bacteria ((Hostutler et al., 2004, Mansfield et al., 2009). This disease has also been described in French bulldogs and a good response to enrofloxacin treatment is common, although resistance has been described (Craven et al., 2010, Manchester et al., 2013). For this reason, it is good practice to sample the colonic mucosa for culture to determine antibiotic susceptibility to guide treatment. Recently guidelines for the use of enrofloxacin for canine colitis have been published (Lechowski et al., 2013); treatment with 10-15mg/kg q24h PO has been suggested, with reassessment after 2 weeks and total treatment duration of 8 weeks in responders.

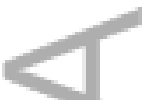

Dogs responding to antibiotics are usually younger dogs of large breed and German Shepherd dogs are overrepresented (Table 4) (German et al., 2001, Allenspach et al., 2016). In Finland, a tylosin response has been 
described in large dogs of middle-age, although an underlying infectious aetiology was not detected (Westermarck et al., 2005). After cessation of antibiotics, relapses are frequent, but control is typically achieved by reintroducing the antibiotic, whereas prevention with probiotic or control with prednisolone cannot be achieved. The effect of tylosin was confirmed in a double-blinded prospective clinical trial and a dosage as low as $5 \mathrm{mg} / \mathrm{kg}$ q $24 \mathrm{~h}$ was found to be effective, with resolution of the diarrhoea within days (Kilpinen et al., 2011, Kilpinen et al., 2014).

Antibiotic treatment is typically recommended for 4 to 6 weeks, but there is no published information to determine the optimal duration. A trial with a one-week course of tylosin had similar success rates to a 6-week course, and there were similar relapse rates of $88 \%$ of dogs within 2 months and $86 \%$ within 30 days respectively (Westermarck et al., 2005, Kilpinen et al., 2014). Based on these 2 studies, treatment duration did not seem to have an effect on rate or time to relapse. Another study raises concerns about long term success in dogs treated with antibiotics: out of 33 dogs responding to metronidazole at a dosage of $15 \mathrm{mg} / \mathrm{kg} \mathrm{q} 12 \mathrm{~h} \mathrm{PO}$, all had relapsed after 6 to 12 months (Allenspach et al., 2016).

Response to both tylosin and metronidazole seems short-lived. This raises questions on how useful antibiotics truly are or whether concurrent treatments are needed to achieve long-term control and long-term use of antibiotics also raises the question of antibiotic resistance (Nitzan et al., 2016). Usually, if an antibiotic trial is started and not successful within 2 weeks, the animal needs to be re-assessed and addition of immunosuppressant drugs considered.

Lympho-plasmacytic inflammation is the most common histologic change in dogs with CE and does not predict to which treatment modality each dog will respond. In rare cases a neutrophilic or granulomatous intestinal infiltrate is observed on histology (Simpson and Jergens, 2011), suggesting that infectious (fungal or bacterial) aetiologies should be considered. Fluorescence in-situ hybridisation (FISH) is a newer and very 
sensitive method to identify bacteria in tissue. FISH can be used on formalin-fixed tissue, which is an advantage over culture in identifying invasive bacteria. Finding bacteria in tissue is an indication for antibiotic treatment. Ideally, repeat biopsies can help to ensure resolution after treatment, although this is rarely performed in clinical practice.

In summary, the use of several antibiotics has been described in dogs with CE. With the exception of granulomatous colitis of boxers and French bulldogs, the efficacy of antibiotics is unclear for most forms of $\mathrm{CE}$ and there is some evidence that responses are short-lived. If an infectious aetiology is suspected, FISH can be helpful to confirm it and, in positive cases, an antibiotic trial can be considered.

\section{Antibiotic-responsive enteropathy - PLE}

No information is available on the use of antibiotics alone for treatment of PLE although few antibioticresponsive cases have been reported (Dossin and Lavoue, 2011). Some PLE dogs present with crypt abscesses, which has been shown to carry a poor prognosis (Willard et al., 2000, Stroda et al., 2012). Although, these changes could potentially represent bacterial infection, no evidence of bacterial association with crypt pathology in Yorkshire terriers was found using FISH (Craven et al., 2009). The question remains as to whether this sample was representative and if a bacterial aetiology might be present in other breeds. As previously noted, FISH is worth considering if there is granulomatous or neutrophilic inflammation and antibiotic coverage might be considered whilst waiting on results in selected individuals.

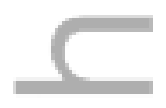

In conclusion, there is currently very little evidence to determine if antibiotics are useful in PLE dogs with crypt abscesses and no information in dogs with other lesions. Future studies looking at bacterial association with PLE and treatment response are needed to assess whether antibiotics have a role in treating these affected dogs. 


\section{Immunosuppressant-responsive enteropathy in dogs with $\mathrm{CE}$}

Studies examining efficacy of immunosuppressant treatment in CE are summarised in Table 5 and usual dosages are shown in Table 3; more detailed information on immunosuppressant therapy can be found elsewhere (Viviano, 2013). Prednisolone has been used extensively in dogs with chronic enteropathy (Jergens and Simpson, 2012). Dogs responding to prednisolone are usually classified as steroid-responsive enteropathy (or diarrhoea) cases, which constitute a subgroup of dogs with immunosuppressant-responsive enteropathy (IRE). Prednisolone is usually used in a step-up manner in dogs with mild to moderate disease (i.e. first diet trial, then antibiotic trial, and then immunosuppressant drugs in the absence of prior response). If the disease is severe, or the dogs have PLE, the animal is usually treated with a combination of corticosteroids and diet with or without antibiotics and treatment is stepped down in responders or stepped up (change of dosage or drugs) in non-responders.

There are now several published studies in dogs using this step-up approach (Table 5). In earlier studies, a variety of immunosuppressant treatments were used and overall response was reported (an exhaustive list can be found in a previous review - (Jergens and Simpson, 2012). For the purpose of this current review, only studies using predominantly 1 immunosuppressant protocol, or comparing 2 protocols, are listed. Immunosuppressant drugs used for CE include prednisolone, azathioprine, budesonide, and cyclosporine. Most of the studies have a short follow-up (less than 6 months) and similar treatment success is reported (over $60 \%)$.

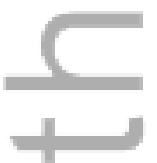

One study compared treatment with prednisolone versus budesonide, with similar remission rates $(>65 \%)$ in both groups over a 6 week period (Dye et al., 2013). One randomized-controlled study looked at the remission in dogs with chronic enteropathy - after exclusion of FRE and ARE - and treated with either prednisolone $(n=25)$ or a combination of prednisolone and metronidazole $(n=29)$ for 21 days (Jergens et al., 2010). The 
remission rate was over $80 \%$ in both groups (no difference), which does not support adding metronidazole to prednisolone for short-term control.

Two studies report the use of cyclosporine (same dose and formulation) in dogs not responding to prednisolone, with variable success ( $25 \%$ vs $79 \%)$. Only 2 dogs out of 8 with CE responded to cyclosporine in 1 study (Allenspach et al., 2007). Another study reports a better outcome with 11 dogs out of 14 responding; 9 of these dogs had CE and 5 PLE and it is unreported to which category the non-responders belong (Allenspach et al., 2006).

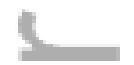

How should 'long-term success' for dogs on immunosuppressant therapy be defined? With prednisolone, amongst dogs classified as IRE only $48 \%$ of success over a 3 year period was reported in a study in Switzerland ( $\mathrm{n}=21)$, and only $12.5 \%$ over a 6-12 month period in a recent British study $(\mathrm{n}=39)$ using several immunosuppressant protocols (Allenspach et al., 2007, Allenspach et al., 2016).

When using cyclosporine as a rescue protocol, 1 study showed more than $70 \%$ response for at least 6 months (mix of dogs with PLE and CE), whereas the other reported 25\% response in dogs with CE over a 3 year follow up (Allenspach et al., 2006, Allenspach et al., 2007). This might reflect differences in dogs studied, but could also suggest only a short-term response to cyclosporine. These results raise the question of long term control in dogs with CE and highlight the need for more studies to address this question. Furthermore, not only remission duration, but differences between treatments need to be assessed. Cyclosporine might play a role as rescue treatment, but differences might exist between PLE and CE dogs, and long-term response need to be further determined.

Interestingly although azathioprine is widely used in IBD in humans to maintain remission, no study is available in dogs with chronic enteropathy (Kim and Choe, 2013). Occasional use amongst other drugs is reported, but no large case series is available (Willard et al., 2000, Craven et al., 2004, Munster et al., 2006, Allenspach et al., 2016). Half the dogs with perianal fistulae in one study had distal colonic inflammation and 
it is uncertain whether these perianal fistulae are an extension of $\mathrm{CE}$ as is observed in people with ulcerative colitis (Jamieson et al., 2002). A prospective study performed in 13 German shepherd dogs and one Border collie with perianal fistulas, using a combination of diet, prednisolone and azathioprine, showed that $57 \%$ had complete remission after 16 weeks (Harkin et al., 2007). The use of different diets and the absence of a control group limit the interpretation. At this stage, information is lacking to determine the usefulness of azathioprine in CE. Anecdotally, other drugs used for CE include chlorambucil and mycophenolate.

In summary, short-term control of CE seems adequate with a variety of immunosuppressant drugs including prednisolone, budesonide, and cyclosporine. Long-term treatment with budesonide has not been studied and prednisolone treatment seems inadequate. Cyclosporine might improve long-term outcome but more studies are needed to determine its true value.

\section{Immunosuppressant-responsive enteropathy in dogs with PLE}

As mentioned above, prognosis is guarded in dogs with PLE, although some Yorkshire terriers do respond well to corticosteroids, diet, and metronidazole (Simmerson et al., 2014). A recent interesting retrospective study looked into prognostic factors in dogs with PLE (Nakashima et al., 2015) and found very different median survival times depending on the final diagnosis. Ninety-two dogs were included and diagnosis was reached by combining histology, and clonality testing by polymerase chain reaction for antigen receptor rearrangement (PARR). Final diagnoses included: CE (including CE and intestinal lymphangiectesia (IL), $\mathrm{n}=62)$, small-cell intestinal lymphoma ( $\mathrm{n}=19)$, and large-cell intestinal lymphoma $(\mathrm{n}=11)$. PLE dogs with large cell lymphoma had the worst prognosis (median survival time of $<100 \mathrm{~d}$ ), followed by small cell lymphoma $(<500 \mathrm{~d})$, whereas CE or IL had the best prognosis $(>1,000 \mathrm{~d})$. Clonality was also found to be a significant negative prognostic factor (regardless of the group) with a median survival time of less than $200 \mathrm{~d}$ compared to over $1,000 \mathrm{~d}$ in the absence of clonality. Finally, high CIBDAI score was predictive of mortality. 
A positive test for clonality (i.e. PARR positive) is suggestive of neoplastic disease, but there are several difficulties with diagnosing intestinal small cell lymphoma in dogs:

- Clonality is sometimes found in suspected inflammatory processes.

- Some cases highly suggestive for small cell lymphoma on histology are negative with PARR

(Nakashima et al., 2015).

- PARR sensitivity depends on the methodology used (Takanosu and Kagawa, 2015).

Although small cell lymphoma has been recognised in cats, it is not as well defined in dogs (Kiupel et al., 2011). One study identified 3 cases of small cell intestinal lymphoma out of 11 dogs when using histology and immunohistochemistry and another reported 2 cases out of 32 using a combination of histology, immunohistochemistry, and PARR testing (Ozaki et al., 2006, Carrasco et al., 2015). Overall, these findings suggest that a proportion of dogs with PLE are likely to have small cell lymphoma although obtaining a final diagnosis is challenging.

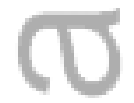

One retrospective study compared PLE dogs treated with azathioprine or chlorambucil. Biopsies were obtained from all dogs and were consistent with CE. None of these dogs were diagnosed with small cell lymphoma on histology, although no specific testing such as PARR or immunohistochemistry was performed. Dogs diagnosed in the first part of the study were treated with a combination of prednisolone and azathioprine (group A) and dogs diagnosed in the second part of the study were treated with prednisolone and chlorambucil (group C) (Dandrieux et al., 2013). Interestingly, Group A was on their first treatment (median: 30 days [range 2 to 599]) for a shorter time than group C (253 days [5 to 494]). At the end of the study, median survival time for group A was 30 days, whereas it was not reached for group C. Even when all censored dogs were taken into account as treatment failures (to represent a worst-case scenario), 6-month survival rate was $15 \%$ in group A and $79 \%$ in group C. Although this study had several limitations (retrospective nature, historical case 
controls, absence of diet standardisation), the difference in outcome between groups was striking and warrants further prospective study.

Chlorambucil is the drug of choice for cats with small cell lymphoma, and associated with a median clinical remission of over 2 years(Stein et al., 2010). The findings of Nakashima (2015) and the possible better outcome in PLE dogs treated with chlorambucil raises the question as to whether a proportion of PLE dogs have small cell lymphoma rather than CE. A prospective study is highly needed to explore this hypothesis further.

Cyclosporine has also been used in PLE dogs that do not respond to corticosteroid treatment, resulting in long-term (3 years) improvement in 7 out of 10 dogs (Allenspach et al., 2007). Another study reports the use of cyclosporine in some refractory cases with only 1 out of 4 dogs responding (Dandrieux et al., 2013).

In conclusion, various immunosuppressant drugs have been used in dogs with PLE. Cyclosporine holds some promise as a rescue agent in dogs that fail prednisolone therapy. Chlorambucil is also likely to have a role to play especially as there is now more evidence that dogs also suffer from small cell lymphoma, but achieving a definitive diagnosis is a first challenge to overcome. Further research is needed to compare different treatment modalities for PLE.

A proportion of Yorkshire terriers with PLE are long-term responders when treated with diet, prednisolone, and metronidazole (Simmerson et al., 2014). However, some are also long-term responders with diet alone (Rudinsky et al., 2014). This highlights the need for further research to understand which dogs will benefit from dietary manipulation alone and which require more aggressive treatment.

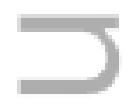

\section{Non-responsive enteropathy in dogs with CE or PLE}

In most studies, there is no response to treatment in 15 to $40 \%$ of dogs in the short-term. Furthermore, longterm response seems to be adequate only in FRE dogs, but not ARE and IRE dogs. This raises questions 
regarding adequacy of our current treatments (especially over the longer term) and the need for new treatments. Ideally, a better understanding of the different pathogeneses leading to CE is needed to obtain an accurate diagnosis and optimal treatment.

The first step for non-responders is to reconsider the diagnosis to ensure that no other disease process has been overlooked. Although some research has been done on gastrointestinal motility, there are few ways to assess it and treat it (Washabau, 2003, Boillat et al., 2010) and, for this reason, motility issues are likely to be underrecognised and under-treated.

The microbiome has been shown to play a central role in several diseases and treatment to alter its constituents, using pre- and probiotics appears promising (Althani et al., 2015). Although few published studies are currently available in veterinary medicine, this domain will definitely further develop. One recent open-label study compared short-term treatment with a probiotic (D-VSL\#3) versus metronidazole and prednisolone in dogs with chronic enteropathy (Rossi et al., 2014). Although both groups responded to treatment, there was some evidence of a possible anti-inflammatory effect after treatment with D-VSL\#3 (increase in FoxP3 and TGF- $\beta^{+}$cells), which was not present in dogs treated with prednisolone. This difference is very intriguing and highlights the need for further research. The reader is directed to recent reviews for more information (Grzeskowiak et al., 2015, Schmitz and Suchodolski, 2016). It is unclear if this type of treatment will be used as an adjunctive or a replacement for current therapies.

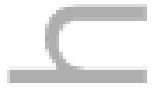

Another promising technique to alter the intestinal flora is faecal transplantation (Brandt and Aroniadis, 2013). The techniques consist of administering faecal material from a "healthy" donor to a patient. Its utility has been accepted in human patients with recurrent Clostridium difficile infection, but it might also successful for other types of GI diseases. Central to the technique is to identify the right diseases and the right donors. There is currently very little information on this topic published in veterinary medicine, although the limited 
information suggests alteration of the microbial flora and a good outcome is achievable (Wesse et al., 2013). There is currently too little information about the use of this technique in dogs to assess its utility, but hopefully more studies will become available in the near future. A recent comment has been published on key aspects for this technique, which will help designing future studies (Chaitman et al., 2016). Another therapy attracting a lot of attention currently is the use of mesenchymal stem cells for the treatment of inflammatory conditions such as CE (Gattegno-Ho et al., 2012). Their effects rely on regenerative as well as antiinflammatory properties. One study has been published in dogs with NRE, with 8 out 11 dogs in remission (decrease in CIBDAI of more than 75\%) at the end of the study (Perez-Merino et al., 2015). Although this study was short (42 days), these are very promising results and further research in this domain is expected.

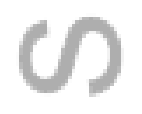

Finally, hypovitaminosis D has been reported in dogs with CE and with PLE (Titmarsh et al., 2015, Gow et al., 2011) and been shown to be a negative prognostic factor in dogs with CE (Titmarsh et al., 2015). There is currently no information regarding vitamin D supplementation or what the impact of this would be in deficient cases.

\section{Conclusion}

CE in dogs encompasses different entities defined by response to medical treatment (Table 6). In contrast, IBD in humans is a disease that requires immunosuppressant drugs and, oftentimes, surgery. When the term IBD is used for dogs, it implies a thorough work-up to exclude extra-intestinal diseases and intestinal diseases such as parasitism, failure to respond to dietary and antibiotic trial, confirmed inflammation on intestinal biopsies, and requirement for immune-modulators. Because some of these steps are often missing, "chronic enteropathy' can be used as an alternative umbrella term. Dogs can then be classified by their response to different trials into the sub-divisions of FRE, ARE, IRE, and NRE. 
It is known that a majority of dogs respond to diet alone in referral centres and it should be considered as the first-line treatment in dogs with mild to moderate disease. Although response to diet was recognised about 10 years ago, it is interesting to note that even in recent studies, most dogs referred for CE are ultimately diagnosed with FRE. This highlights the importance of: (a) performing a proper diet trial prior to referral; and, (b) ensuring owner compliance by explaining the reason and duration of the trial. It is likely that compliance is enhanced in owners agreeing to referral. However, hopefully more clients in general practice can be persuaded to comply with a strict diet trial after highlighting the high prevalence of FRE. Compliance might increase if owners clearly understand that no other treatment than a food change is needed in a majority of dogs to reach long term resolution (clinically and ultrastructurally).

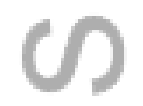

If an immunosuppressant is needed, both prednisolone and budesonide have shown good short-term success. It is worth noting that systemic corticosteroid side-effects have also been seen with budesonide. There is some evidence to suggest that cyclosporine is a good choice in a proportion of non-responders. In any case, long term response to immunosuppressant remains inadequate and further research is needed to improve the outcome for these dogs.

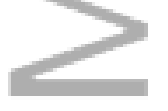

PLE dogs present another challenge, with fewer studies available to guide treatment. New insight suggests that some dogs will respond to food alone, although the challenge is to select the right candidate for a diet trial. It is likely to be an adequate choice for at least a short duration (i.e. 1 week) in dogs that are clinically well and with good appetite. In the absence of response, treatment should be escalated. There is also building evidence thăt some PLE dogs have intestinal small cell lymphoma. Improved diagnostic tools are needed to identify these cases early to implement more aggressive treatment, which might include chlorambucil as has been described in cats.

There is a paucity of well-designed studies looking at the optimal treatment for dogs with CE. These are needed to help the clinician decide how to best manage these cases. Long-term control of dogs with CE seems 
adequate for FRE, but not for ARE and IRE. Ideally, more prospective studies with both short and long term follow up will be conducted to identify the most successful treatments for each type of CE and further define our management of this challenging disease.

\section{REFERENCES}

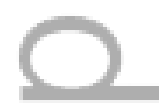

ALLENSPACH, K., CULVERWELL, C. \& CHAN, D. 2016. Long-term outcome in dogs with chronic enteropathies: 203 cases. Vet Rec.

ALLENSPACH, K., RUFENACHT, S., SAUTER, S., GRONE, A., STEFFAN, J., STREHLAU, G. \& GASCHEN, F. 2006. Pharmacokinetics and clinical efficacy of cyclosporine treatment of dogs with steroid-refractory inflammatory bowel disease. J Vet Intern Med, 20, 239-44.

ALLENSPACH, K., WIELAND, B., GRONE, A. \& GASCHEN, F. 2007. Chronic enteropathies in dogs: evaluation of risk factors for negative outcome. J Vet Intern Med, 21, 700-8.

ALTHANI, A., MAREI, H. E., HAMDI, W. S., NASRALLAH, G. K., EL ZOWALATY, M. E., AL KHDOR, S., AL-ASMAKH, M. \& ABDEL-AZIZ, H. 2015. Human Microbiome and Its Association With Health and Diseases. J Cell Physiol.

ANNESE, V., DURICOVA, D., GOWER-ROUSSEAU, C., JESS, T. \& LANGHOLZ, E. 2016. Impact of New Treatments on Hospitalisation, Surgery, Infection, and Mortality in IBD: a Focus Paper by the Epidemiology Committee of ECCO. J Crohns Colitis, 10, 216-25.

BOILLAT, C. S., GASCHEN, F. P., GASCHEN, L., STOUT, R. W. \& HOSGOOD, G. L. 2010. Variability associated with repeated measurements of gastrointestinal tract motility in dogs obtained by use of a wireless motility capsule system and scintigraphy. Am J Vet Res, 71, 903-8.

BRANDT, L. J. \& ARONIADIS, O. C. 2013. An overview of fecal microbiota transplantation: techniques, indications, and outcomes. Gastrointest Endosc, 78, 240-9.

CARRASCO, V., RODRIGUEZ-BERTOS, A., RODRIGUEZ-FRANCO, F., WISE, A. G., MAES, R., MULLANEY, T. \& KIUPEL, M. 2015. Distinguishing Intestinal Lymphoma From Inflammatory Bowel Disease in Canine Duodenal Endoscopic Biopsy Samples. Vet Pathol, 52, 668-75.

CHAITMAN, J., JERGENS, A. E., GASCHEN, F., GARCIA-MAZCORRO, J. F., MARKS, S. L., MARROQUINCARDONA, A. G., RICHTER, K., ROSSI, G., SUCHODOLSKI, J. S. \& WESSE, J. S. 2016. Commentary on key aspects of fecal microbiota transplantation in small animal practice. Veterinary medicine: Research and Reports, 7, 71-74.

CRAVEN, M., DOGAN, B., SCHUKKEN, A., VOLKMAN, M., CHANDLER, A., MCDONOUGH, P. L. \& SIMPSON, K. W. 2010. Antimicrobial resistance impacts clinical outcome of granulomatous colitis in boxer dogs. $J$ Vet Intern Med, 24, 819-24.

CRAVEN, M., DUHAMEL, G. E., SUTTER, N. B. \& SIMPSON, K. W. 2009. Absence of bacterial association in Yorkshire terriers with protein-losing eneteropathy and cystic intestinal crypts. J Vet Intern Med, 23, 757.

CRAVEN, M., SIMPSON, J. W., RIDYARD, A. E. \& CHANDLER, M. L. 2004. Canine inflammatory bowel disease: retrospective analysis of diagnosis and outcome in 80 cases (1995-2002). J Small Anim Pract, 45, 336-42. 
DANDRIEUX, J. R., NOBLE, P. J., SCASE, T. J., CRIPPS, P. J. \& GERMAN, A. J. 2013. Comparison of a chlorambucil-prednisolone combination with an azathioprine-prednisolone combination for treatment of chronic enteropathy with concurrent protein-losing enteropathy in dogs: 27 cases (2007-2010). J Am Vet Med Assoc, 242, 1705-14.

DAVE, M. \& LOFTUS, E. V., JR. 2012. Mucosal healing in inflammatory bowel disease-a true paradigm of success? Gastroenterol Hepatol (N Y), 8, 29-38.

DE SOUZA, H. S. \& FIOCCHI, C. 2016. Immunopathogenesis of IBD: current state of the art. Nat Rev Gastroenterol Hepatol, 13, 13-27.

DIJKSTRA, M., KRAUS, J. S., BOSJE, J. T. \& DEN HERTOG, E. 2010. [Protein-losing enteropathy in Rottweilers]. Tijdschr Diergeneeskd, 135, 406-12.

DOSSIN, O. \& LAVOUE, R. 2011. Protein-losing enteropathies in dogs. Vet Clin North Am Small Anim Pract, 41, 399-418.

DYE, T. L., DIEHL, K. J., WHEELER, S. L. \& WESTFALL, D. S. 2013. Randomized, controlled trial of budesonide and prednisone for the treatment of idiopathic inflammatory bowel disease in dogs. J Vet Intern Med, 27, 1385-91.

EQUILINO, M., THEODOLOZ, V., GORGAS, D., DOHERR, M. G., HEILMANN, R. M., SUCHODOLSKI, J. S., STEINER, J. M. \& BURGENER DVM, I. A. 2015. Evaluation of serum biochemical marker concentrations and survival time in dogs with protein-losing enteropathy. J Am Vet Med Assoc, 246, 91-9.

GARCIA-SANCHO, M., RODRIGUEZ-FRANCO, F., SAINZ, A., MANCHO, C. \& RODRIGUEZ, A. 2007. Evaluation of clinical, macroscopic, and histopathologic response to treatment in nonhypoproteinemic dogs with lymphocytic-plasmacytic enteritis. J Vet Intern Med, 21, 11-7.

GASCHEN, F. P. \& MERCHANT, S. R. 2011. Adverse food reactions in dogs and cats. Vet Clin North Am Small Anim Pract, 41, 361-79.

GATTEGNO-HO, D., ARGYLE, S. A. \& ARGYLE, D. J. 2012. Stem cells and veterinary medicine: tools to understand diseases and enable tissue regeneration and drug discovery. Vet J, 191, 19-27.

GERMAN, A. J., HALL, E. J. \& DAY, M. J. 2001. Immune cell populations within the duodenal mucosa of dogs with enteropathies. J Vet Intern Med, 15, 14-25.

GOODWIN, L. V., GOGGS, R., CHAN, D. L. \& ALLENSPACH, K. 2011. Hypercoagulability in dogs with proteinlosing enteropathy. J Vet Intern Med, 25, 273-7.

GOW, A. G., ELSE, R., EVANS, H., BERRY, J. L., HERRTAGE, M. E. \& MELLANBY, R. J. 2011. Hypovitaminosis D in dogs with inflammatory bowel disease and hypoalbuminaemia. J Small Anim Pract, 52, 411-8.

GREVENITIS, P., THOMAS, A. \& LODHIA, N. 2015. Medical Therapy for Inflammatory Bowel Disease. Surg Clin North Am, 95, 1159-82.

GRZESKOWIAK, L., ENDO, A., BEASLEY, S. \& SALMINEN, S. 2015. Microbiota and probiotics in canine and feline welfare. Anaerobe, 34, 14-23.

HALL, E. J. 2011. Antibiotic-responsive diarrhea in small animals. Vet Clin North Am Small Anim Pract, 41, 273-86.

HARKIN, K. R., PHILLIPS, D. \& WILKERSON, M. 2007. Evaluation of azathioprine on lesion severity and lymphocyte blastogenesis in dogs with perianal fistulas. J Am Anim Hosp Assoc, 43, 21-6.

HONNEFFER, J. B., MINAMOTO, Y. \& SUCHODOLSKI, J. S. 2014. Microbiota alterations in acute and chronic gastrointestinal inflammation of cats and dogs. World J Gastroenterol, 20, 16489-97.

HOSTUTLER, R. A., LURIA, B. J., JOHNSON, S. E., WEISBRODE, S. E., SHERDING, R. G., JAEGER, J. Q. \& GUILFORD, W. G. 2004. Antibiotic-responsive histiocytic ulcerative colitis in 9 dogs. J Vet Intern Med, $18,499-504$.

This article is protected by copyright. All rights reserved. 
JAMIESON, P. M., SIMPSON, J. W., KIRBY, B. M. \& ELSE, R. W. 2002. Association between anal furunculosis and colitis in the dog: preliminary observations. J Small Anim Pract, 43, 109-14.

JERGENS, A. E., CRANDELL, J., MORRISON, J. A., DEITZ, K., PRESSEL, M., ACKERMANN, M., SUCHODOLSKI, J. S., STEINER, J. M. \& EVANS, R. 2010. Comparison of oral prednisone and prednisone combined with metronidazole for induction therapy of canine inflammatory bowel disease: a randomized-controlled trial. J Vet Intern Med, 24, 269-77.

JERGENS, A. E., SCHREINER, C. A., FRANK, D. E., NIYO, Y., AHRENS, F. E., ECKERSALL, P. D., BENSON, T. J. \& EVANS, R. 2003. A scoring index for disease activity in canine inflammatory bowel disease. $J$ Vet Intern Med, 17, 291-7.

JERGENS, A. E. \& SIMPSON, K. W. 2012. Inflammatory bowel disease in veterinary medicine. Front Biosci (Elite Ed), 4, 1404-19.

KATHRANI, A., WERLING, D. \& ALLENSPACH, K. 2011. Canine breeds at high risk of developing inflammatory bowel disease in the south-eastern UK. Vet Rec, 169, 635.

KILPINEN, S., SPILLMANN, T., SYRJA, P., SKRZYPCZAK, T., LOUHELAINEN, M. \& WESTERMARCK, E. 2011. Effect of tylosin on dogs with suspected tylosin-responsive diarrhea: a placebo-controlled, randomized, double-blinded, prospective clinical trial. Acta Vet Scand, 53, 26.

KILPINEN, S., SPILLMANN, T. \& WESTERMARCK, E. 2014. Efficacy of two low-dose oral tylosin regimens in controlling the relapse of diarrhea in dogs with tylosin-responsive diarrhea: a prospective, singleblinded, two-arm parallel, clinical field trial. Acta Vet Scand, 56, 43.

KIM, M. J. \& CHOE, Y. H. 2013. Monitoring and Safety of Azathioprine Therapy in Inflammatory Bowel Disease. Pediatr Gastroenterol Hepatol Nutr, 16, 65-70.

KIUPEL, M., SMEDLEY, R. C., PFENT, C., XIE, Y., XUE, Y., WISE, A. G., DEVAUL, J. M. \& MAES, R. K. 2011. Diagnostic algorithm to differentiate lymphoma from inflammation in feline small intestinal biopsy samples. Vet Pathol, 48, 212-22.

LECHOWSKI, R., COTARD, J. P., BOULOUIS, H. J., KIETZMAN, M., FARCA, A. M., FONTAINE, J., CANEY, S., DUPREE, G. \& GROUP, R. 2013. Proper use of quinolones for canine colitis ambulatory treatment: literature review and REQUEST guidelines. Pol J Vet Sci, 16, 193-7.

LITTMAN, M. P., DAMBACH, D. M., VADEN, S. L. \& GIGER, U. 2000. Familial protein-losing enteropathy and protein-losing nephropathy in Soft Coated Wheaten Terriers: 222 cases (1983-1997). J Vet Intern Med, 14, 68-80.

LUCKSCHANDER, N., ALLENSPACH, K., HALL, J., SEIBOLD, F., GRONE, A., DOHERR, M. G. \& GASCHEN, F. 2006. Perinuclear antineutrophilic cytoplasmic antibody and response to treatment in diarrheic dogs with food responsive disease or inflammatory bowel disease. J Vet Intern Med, 20, 221-7.

MANCHESTER, A. C., HILL, S., SABATINO, B., ARMENTANO, R., CARROLL, M., KESSLER, B., MILLER, M., DOGAN, B., MCDONOUGH, S. P. \& SIMPSON, K. W. 2013. Association between granulomatous colitis in French Bulldogs and invasive Escherichia coli and response to fluoroquinolone antimicrobials. $J$ Vet Intern Med, 27, 56-61.

MANDIGERS, P. J., BIOURGE, V., VAN DEN INGH, T. S., ANKRINGA, N. \& GERMAN, A. J. 2010. A randomized, open-label, positively-controlled field trial of a hydrolyzed protein diet in dogs with chronic small bowel enteropathy. J Vet Intern Med, 24, 1350-7.

MANSFIELD, C. S., JAMES, F. E., CRAVEN, M., DAVIES, D. R., O'HARA, A. J., NICHOLLS, P. K., DOGAN, B., MACDONOUGH, S. P. \& SIMPSON, K. W. 2009. Remission of histiocytic ulcerative colitis in Boxer dogs correlates with eradication of invasive intramucosal Escherichia coli. J Vet Intern Med, 23, 964-9.

MARKS, S. L., LAFLAMME, D. P. \& MCALOOSE, D. 2002. Dietary trial using a commercial hypoallergenic diet containing hydrolyzed protein for dogs with inflammatory bowel disease. Vet Ther, 3, 109-18. 
MUNSTER, M., HORAUF, A. \& BILZER, T. 2006. [Assessment of disease severity and outcome of dietary, antibiotic, and immunosuppressive interventions by use of the canine IBD activity index in 21 dogs with chronic inflammatory bowel disease]. Berl Munch Tierarztl Wochenschr, 119, 493-505.

NAKASHIMA, K., HIYOSHI, S., OHNO, K., UCHIDA, K., GOTO-KOSHINO, Y., MAEDA, S., MIZUTANI, N., TAKEUCHI, A. \& TSUIMOTO, H. 2015. Prognostic factors in dogs with protein-losing enteropathy. Vet $J, 205,28-32$.

NITZAN, O., ELIAS, M., PERETZ, A. \& SALIBA, W. 2016. Role of antibiotics for treatment of inflammatory bowel disease. World J Gastroenterol, 22, 1078-87.

OKANISHI, H., YOSHIOKA, R., KAGAWA, Y. \& WATARI, T. 2014. The clinical efficacy of dietary fat restriction in treatment of dogs with intestinal lymphangiectasia. J Vet Intern Med, 28, 809-17.

OWENS, S. L., PARNELL, N. K. \& MOORE, G. E. 2011. Canine protein losing enteropathy: a retrospective analysis and survival study in 68 dogs. J Vet Intern Med, 25, 692-3.

OZAKI, K., YAMAGAMI, T., NOMURA, K. \& NARAMA, I. 2006. T-cell lymphoma with eosinophilic infiltration involving the intestinal tract in 11 dogs. Vet Pathol, 43, 339-44.

PEREZ-MERINO, E. M., USON-CASAUS, J. M., DUQUE-CARRASCO, J., ZARAGOZA-BAYLE, C., MARINAS-PARDO, L., HERMIDA-PRIETO, M., VILAFRANCA-COMPTE, M., BARRERA-CHACON, R. \& GUALTIERI, M. 2015. Safety and efficacy of allogeneic adipose tissue-derived mesenchymal stem cells for treatment of dogs with inflammatory bowel disease: Endoscopic and histological outcomes. Vet J, 206, 391-7.

PETERSON, P. B. \& WILLARD, M. D. 2003. Protein-losing enteropathies. Vet Clin North Am Small Anim Pract, 33, 1061-82.

ROSSI, G., PENGO, G., CALDIN, M., PALUMBO PICCIONELLO, A., STEINER, J. M., COHEN, N. D., JERGENS, A. E. \& SUCHODOLSKI, J. S. 2014. Comparison of microbiological, histological, and immunomodulatory parameters in response to treatment with either combination therapy with prednisone and metronidazole or probiotic VSL\#3 strains in dogs with idiopathic inflammatory bowel disease. PLoS One, 9, e94699.

RUAUX, C. G. 2013. Cobalamin in companion animals: diagnostic marker, deficiency states and therapeutic implications. Vet J, 196, 145-52.

RUDINSKY, A. J., HOWARD, J. P., BISHOP, M. A., SHERDING, R. G., PARKER, V. J. \& GILOR, C. 2014. Dietary management of protein-losing enteropathy in Yorkshire terriers. J Anim Physiol Anim Nutr (Berl), 98, 1199.

SCHMITZ, S. \& SUCHODOLSKI, J. 2016. Understanding the canine intestinal microbiota and its modification by pro-, pre- and synbiotics - what is the evidence? Veterinary Medicine and Science.

SCHREINER, N. M., GASCHEN, F., GRONE, A., SAUTER, S. N. \& ALLENSPACH, K. 2008. Clinical signs, histology, and CD3-positive cells before and after treatment of dogs with chronic enteropathies. J Vet Intern Med, 22, 1079-83.

SIMMERSON, S. M., ARMSTRONG, P. J., WUNSCHMANN, A., JESSEN, C. R., CREWS, L. J. \& WASHABAU, R. J. 2014. Clinical features, intestinal histopathology, and outcome in protein-losing enteropathy in Yorkshire Terrier dogs. J Vet Intern Med, 28, 331-7.

SIMPSON, K. W. \& JERGENS, A. E. 2011. Pitfalls and progress in the diagnosis and management of canine inflammatory bowel disease. Vet Clin North Am Small Anim Pract, 41, 381-98.

STEIN, T. J., PELLIN, M., STEINBERG, H. \& CHUN, R. 2010. Treatment of feline gastrointestinal small-cell lymphoma with chlorambucil and glucocorticoids. J Am Anim Hosp Assoc, 46, 413-7.

STRODA, K., WAKAMATSU, N., GASCHEN, L., KEARNEY, M. \& GASCHEN, F. 2012. Histopathological, clinical, endoscopic, and ultrasound features of dogs with chronic enteropathies and small intestinal crypt lesions. J Vet Intern Med, 26, 767-8.

This article is protected by copyright. All rights reserved. 
TAKANOSU, M. \& KAGAWA, Y. 2015. Comparison of primer sets for T-cell clonality testing in canine intestinal lymphoma. J Vet Diagn Invest, 27, 645-50.

TITMARSH, H., GOW, A. G., KILPATRICK, S., SINCLAIR, J., HILL, T., MILNE, E., PHILBEY, A., BERRY, J., HANDEL, I. \& MELLANBY, R. J. 2015. Association of Vitamin D Status and Clinical Outcome in Dogs with a Chronic Enteropathy. J Vet Intern Med, 29, 1473-8.

VAN KRUININGEN, H. J., LEES, G. E., HAYDEN, D. W., MEUTEN, D. J. \& WA., R. 1984. Lipogranulomatous lymphangitis in canine intestinal lymphangiectasia. Vet Pathol, 21, 377-383.

VESTER-ANDERSEN, M. K., PROSBERG, M. V., JESS, T., ANDERSSON, M., BENGTSSON, B. G., BLIXT, T., MUNKHOLM, P., BENDTSEN, F. \& VIND, I. 2014. Disease course and surgery rates in inflammatory bowel disease: a population-based, 7-year follow-up study in the era of immunomodulating therapy. Am J Gastroenterol, 109, 705-14.

VIVIANO, K. R. 2013. Update on immununosuppressive therapies for dogs and cats. Vet Clin North Am Small Anim Pract, 43, 1149-70.

WALKER, D., KNUCHEL-TAKANO, A., MCCUTCHAN, A., CHANG, Y. M., DOWNES, C., MILLER, S., STEVENS, K., VERHEYEN, K., PHILLIPS, A. D., MIAH, S., TURMAINE, M., HIBBERT, A., STEINER, J. M., SUCHODOLSKI, J. S., MOHAN, K., EASTWOOD, J., ALLENSPACH, K., SMITH, K. \& GARDEN, O. A. 2013. A comprehensive pathological survey of duodenal biopsies from dogs with diet-responsive chronic enteropathy. J Vet Intern Med, 27, 862-74.

WASHABAU, R. J. 2003. Gastrointestinal motility disorders and gastrointestinal prokinetic therapy. Vet Clin North Am Small Anim Pract, 33, 1007-28, vi.

WATSON, V. E., HOBDAY, M. M. \& DURHAM, A. C. 2014. Focal intestinal lipogranulomatous lymphangitis in 6 dogs (2008-2011). J Vet Intern Med, 28, 48-51.

WESSE, J. S., COSTA, M. C. \& WEBB, J. A. 2013. Preliminary clinical and microbiome assessment of stool transplantation in the dog and cat. $J$ Vet Intern Med, 27, 705.

WESTERMARCK, E., SKRZYPCZAK, T., HARMOINEN, J., STEINER, J. M., RUAUX, C. G., WILLIAMS, D. A., EEROLA, E., SUNDBACK, P. \& RINKINEN, M. 2005. Tylosin-responsive chronic diarrhea in dogs. J Vet Intern Med, 19, 177-86.

WILLARD, M. D., HELMAN, G., FRADKIN, J. M., BECKER, T., BROWN, R. M., LEWIS, B. C. \& WEEKS, B. R. 2000. Intestinal crypt lesions associated with protein-losing enteropathy in the dog. J Vet Intern Med, 14, 298-307.

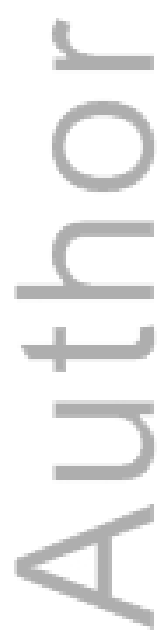

This article is protected by copyright. All rights reserved. 
Inflammatory bowel disease versus chronic enteropathy in dogs: Are they one and the same?

Words: 5644

Julien R. S. Dandrieux BSc Dr med vet DACVIM (SAIM)

Faculty of Veterinary and Agricultural Sciences

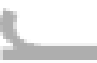

Translational Research and Animal Clinical Trial Study (TRACTS) Group

The University of Melbourne

250 Princes Highway

Werribee -3030

Victoria - Australia

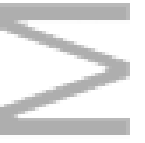

Email:jdandrieux@gmail.com

Phone number: +61 (0) 397312000

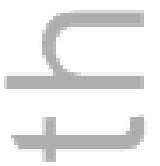

Acknowledgment: The author would like to thank Drs Josephine Dandrieux and Lauren Lacorcia for critical review of this manuscript.

\section{Grants}

- Melbourne International Research Scholarship (MIRS)

- Melbourne International Fee Remission (MIFR) 


\section{University Library}

\section{- M M N E R VA A gateway to Melbourne's research publications}

Minerva Access is the Institutional Repository of The University of Melbourne

Author/s:

Dandrieux, JRS

Title:

Inflammatory bowel disease versus chronic enteropathy in dogs: are they one and the same?

Date:

2016-11-01

Citation:

Dandrieux, J. R. S. (2016). Inflammatory bowel disease versus chronic enteropathy in dogs: are they one and the same? JOURNAL OF SMALL ANIMAL PRACTICE, 57 (11), pp.589-599. https://doi.org/10.1111/jsap.12588.

Persistent Link:

http://hdl.handle.net/11343/291847 